ESTUDOS R:E?

\title{
Uma experiência de formação de professores nos anos 80: lições de uma história
}

Lúcia Velloso Maurício

\section{Resumo}

A Faculdade de Formação de Professores (FFP) da Universidade Estadual do Rio de Janeiro (Uerj) vivenciou um projeto chamado Complexo Educacional de São Gonçalo (Cesg), que se desenvolveu no período da redemocratização brasileira, de 1984 a 1986. Deixou escassos documentos escritos, agravando seu desconhecimento. Este trabalho reuniu documentos e estudos disponíveis para contribuir com a reconstituição da história da faculdade, trazendo a versão dos implementadores do projeto. Na perspectiva da nova história cultural, entende-se que a história se constitui por organização de sentidos que se tornam hegemônicos. O projeto Cesg desvela concepção de formação que tem o professor como eixo para a construção do sistema público de ensino, apesar dos descaminhos que não podem ser atribuídos apenas a Darcy Ribeiro, idealizador do projeto.

Palavras-chave: história cultural; formação de professores; Escola de Demonstração; redemocratização. 


\section{Abstract \\ Teachers' education: an experience in the eighties}

The College of Teachers Education (FFP) at UERJ, experienced a project named São Gonçalo Educational Complex (CESG) which was developed during the Brazilian re-democratization period, between 1984 and 1986. Few written documents remained, so it became an almost unknown time. This paper gathered documents and studies available to contribute to the reconstruction of the institutional history, bringing the version of project implementers. Under the perspective of the New Cultural History, it is understood that the history is told by the organization of the senses that become hegemonic. The CESG project reveals a conception in which the teacher formation is the axis for the construction of the public school system, despite the project mistakes that cannot be attributed only to Darcy Ribeiro, its creator.

Keywords: cultural history; teachers' education; demonstration school; re-democratization.

\section{Uma história entre histórias}

Tomando como referência teórica a nova história cultural, entende-se que a história se constitui por organização de sentidos que se tornam hegemônicos. A história é escrita no contexto de relações humanas, portanto, está ligada mais às práticas do que ao tempo (Nunes, 2004). Por outro lado, nem sempre é possível fazer a reconstituição histórica de uma instituição por meio de documentos, pois muitas vezes eles são insuficientes ou simplesmente não é possível acessá-los. Documentos como autobiografias, memórias e diários têm colaborado para a reconstituição de processos educativos de outras épocas ou lugares, mediante testemunhos de gerações ou grupos sociais, desde que foi alargada a compreensão do que constitui fonte histórica. O uso do espaço e do tempo consolidando diversas culturas escolares, a representação de professores sobre si mesmos ou sobre suas práticas são exemplos da riqueza destas fontes para o estudo do cotidiano da educação (Lopes, Galvão, 2005).

São as perguntas do presente que nos levam ao passado; então, estudá-lo pode trazer luz a problemas fundamentais da atualidade, como a chamada crise da escola. Para entender esta crise, é necessário rastrear a trajetória da instituição. Os arquivos de escolas ajudam a compreender problemas da produção da memória, inclusive pela evidência mesma de sua destruição. A própria utilização dos registros escolares, em geral 
desfalcados, vai ajudando a espalhar a consciência da importância de sua preservação. Quando as instituições educacionais começam a organizar sua memória em pequenos museus, exposições, acervos fotográficos, por meio de testemunhos que preenchem lacunas de memória institucional, estão contribuindo para a construção da história e para o entendimento da permanência ou crise da forma escolar (Vincent, Lahire, Thin, 2001).

A Faculdade de Formação de Professores (FFP) da Universidade do Estado do Rio de Janeiro (Uerj), em São Gonçalo, RJ, deixou escassos documentos escritos sobre uma experiência de formação em serviço da década de 80, permitindo que sobrevivesse apenas a memória de alguns participantes, costurada por interesses corporativos do passado. Este trabalho buscou apresentar a versão dos implementadores do projeto chamado Complexo Educacional de São Gonçalo (Cesg), que envolveu a FFP de 1984 a 1986, reunindo os escassos documentos de referência e fragmentos de informações antes que o esgarçamento das lembranças dos participantes dificultasse ainda mais a reconstituição da experiência. Assim, mesmo reconhecendo, como afirmam Lopes e Galvão (2005), que muitas pesquisas na área da educação enfocam mais o que deveria ter acontecido do que o que de fato se deu, aqui a contribuição restringe-se a elucidar a proposta que orientou as ações que se desenvolveram no período, inseridas no seu contexto; são relatados também os descaminhos do projeto que não podem ser atribuídos tão somente a vaidades ou personalismo do professor Darcy Ribeiro, idealizador do projeto.

\section{Cenário da redemocratização}

O Programa Especial de Educação (PEE), responsável pelo desenvolvimento do Cesg, foi gestado no período de retomada da democracia no Brasil. Foi uma época de intensa agitação política, com reorganização de entidades representativas da sociedade civil, por um lado, e atentados da direita, por outro: em 1978, houve o fim da censura prévia e do Ato Institucional $n^{\circ} 5$, que deu amparo legal às arbitrariedades da ditadura militar; em 1979, a Lei da Anistia propiciou o retorno dos exilados; em 1980, assistiu-se à destruição de importante símbolo da luta contra a ditadura, a sede da União Nacional de Estudantes (UNE); no mesmo ano, presenciaram-se atentados a bomba e sequestros por grupos de militares contrários à redemocratização; em 1981, houve o atentado do Riocentro, culminância da impunidade dos grupos de extrema-direita; em 1982, finalmente, participamos da eleição direta para governador, após 18 anos, mas não se conseguiu ainda o pleito direto para presidente da República.

Na área específica da educação, entre 1978 e 1979, houve greve de professores da rede pública de ensino fundamental em todos os grandes Estados brasileiros. Foram criados nesse mesmo período a Associação Nacional de Pós-Graduação em Educação (ANPEd), o Centro de Estudos de Educação e Sociedade (Cedes) e a Associação Nacional de Educação (Ande), que realizaram a $1{ }^{\text {a }}$ Conferência Brasileira de Educação (CBE) em 
1980, em São Paulo, com 1.400 participantes, lançando um manifesto. Nesse mesmo ano, a reunião da Sociedade Brasileira para o Progresso da Ciência (SBPC), no Rio de Janeiro, teve como tema Ciência e educação na sociedade democrática. Em 1981 foi aprovada Emenda Constitucional que garantiu aposentadoria especial para professores e professoras após 30 e 25 anos de serviço, respectivamente, com salário integral (Brasil, 1981); em 1982, a $2^{\text {a }}$ CBE reuniu 2.000 participantes em Belo Horizonte, onde discutiram Educação: perspectiva na democratização da sociedade.

Os governos estaduais empossados em março de 1983 tiveram seus programas influenciados pelos debates que se travaram nos anos de 1978 a 1982. As propostas de governo para a retomada da democracia não eram únicas; todos os partidos recém-criados tentavam consolidar sua linha política em diversas áreas, inclusive na de educação. No dia em que assumiu o governo do Estado do Rio de Janeiro, Leonel Brizola nomeou a Comissão Coordenadora de Educação e Cultura, presidida por Darcy Ribeiro, vice-governador e secretário de Cultura do Estado do Rio de Janeiro, e integrada pelas secretárias de Educação do Estado e do Município do Rio de Janeiro, respectivamente, Iara Vargas e Maria Yedda Linhares. Esse foi o órgão máximo de decisão e executor do PEE.

O ano de 1984, em que foi publicado o orçamento e começaram as obras de construção dos Centros Integrados de Educação Pública (Cieps), ${ }^{1}$ maior projeto desenvolvido pelo PEE, assistiu a rude debate nos jornais entre Darcy Ribeiro e Vanilda Paiva a respeito do programa dos Cieps, denominados "escolas-mamute", o que foi revidado com "pedagogia vadia". Vários educadores posicionaram-se de lado a lado, aprofundando-se o fosso entre academia e política de educação implementada. O tema da $3^{\text {a }} \mathrm{CBE}$, Da crítica às propostas de ação, que reuniu 5.000 participantes, deixa nas entrelinhas este acirramento de posições, porque tanto pode ser lido como partindo das críticas para a formulação de propostas de ação como discutindo a crítica às propostas de ação. A conferência, que ocorreu em Niterói, no Estado do Rio de Janeiro, onde se implantava a política dos Cieps, foi organizada por instituições de pesquisa (ANPEd/ Cedes) e entidades sindicais (Andes/CEP²), com grande presença de militantes partidários e de estudantes. A proposta de educação de Darcy Ribeiro desenvolveu-se, continuamente, na tensão entre o que se realizava e a repercussão que viabilizaria a virtual candidatura de Leonel Brizola à presidência da República. O desenvolvimento do Cesg está inserido neste contexto de disputa político-partidária (Mauricio, 1990).

\section{Escola de Demonstração}

O Cesg teve início com a nomeação de um grupo de trabalho, em dezembro de 1983, para avaliar a viabilidade de implantação do projeto. Sua localização em São Gonçalo foi fruto de uma casualidade que atendia a várias metas da programação educacional do Governo Brizola, instalado em março de 1983: no bairro Paraíso, três unidades escolares pertencentes
1 Prédio escolar projetado por Oscar Niemeyer para atender a 700 crianças em turno completo, com projeto pedagógico que integrava educação, saúde e cultura.

${ }^{2} \mathrm{Na}$ época Centro Estadual de Professores; hoje Sindicato Estadual de Profissionais da Educação (Sepe). 
${ }^{3}$ Foi mantida a terminologia da época: $1^{\circ}$ e $2^{\circ}$ graus.

${ }^{4}$ As teses, na versão educacional, foram publicadas em novembro de 1983, no jornal Escola Viva número 1, enviado para cada professor de todas as escolas públicas do Estado e do município do Rio de Janeiro. Todas as escolas pararam um dia para discuti-las e elegeram dois representantes por escola para a fase regional do Encontro. Nova discussão e cada região elegeu representantes, compondo um fórum de 100 professores para o Encontro final ocorrido em Mendes, RJ; as teses reformuladas após o Encontro foram publicadas em dezembro de 1983 no jornal Escola Viva número 2. ao Estado margeavam um terreno disputado há décadas na Justiça por vários interessados, entre eles o próprio Estado. O terreno, conhecido como Patronato era imenso e junto à rua principal, tornando-se muito valorizado pela especulação imobiliária.

As escolas lá instaladas não tinham qualquer relação interinstitucional, como costuma ocorrer no Estado: a FFP, cujo momento de realizações e recursos se perdera desde a fusão do Estado do Rio de Janeiro com o da Guanabara, oferecia na época cursos noturnos de licenciatura curta; o Centro Interescolar Walter Orlandine (CIWO), bem construído e equipado pelo convênio MEC-Bird, cuja ociosidade chocava a carência local de vagas para o $2^{\circ}$ grau; $^{3}$ e a lúgubre Escola Estadual Coronel João Tarcísio Bueno, de $1^{\circ}$ grau, com quatro turnos, cerca de 3.000 alunos, sem mobiliário, com instalações insalubres. Aí estava o acaso: a proximidade física das três unidades estaduais, atendendo a diferentes graus de ensino, em torno de um terreno de fácil acesso, de grandes proporções, pertencente ao Estado. E mais: a faculdade era de formação de professores. Este conjunto atendia a várias metas da proposta de educação do governo estadual.

As diretrizes educacionais do Governo Brizola foram discutidas no Primeiro Encontro de Professores do Primeiro Grau da Rede Pública do Estado do Rio de Janeiro ${ }^{4}$ e publicadas no Plano de Desenvolvimento Econômico e Social do Estado do Rio de Janeiro de 1984 a 1987. O Plano e as teses diferem na linguagem, mas coincidem nas prioridades. As diferenças entre a forma original e a versão final resultaram dos debates ocorridos no Encontro de Mendes.

As teses eram divididas em três blocos: 1) Análise crítica da situação da escola pública; 2) Metas da programação educacional do governo; 3) Papel e participação dos professores na nova programação educacional. Aqui se apresentam apenas as metas que mantinham relação com o Cesg:

1. "... acabar com o terceiro turno, garantindo a cada criança cinco horas diárias de permanência na escola...";

2. "... dar ao professorado, através de cursos de reciclagem, a ajuda que ele requer para o pleno cumprimento de suas funções...";

13. "... a implantação de uma série de centros culturais comunitários, cuja finalidade será receber as crianças para cinco horas adicionais, antes ou depois das aulas, para dar-lhes uma refeição, estudo dirigido e atividades culturais e recreativas.";

16. "... a criação, na cidade do Rio de Janeiro e no Estado, de diversas Escolas de Demonstração, a serem implantadas nos locais onde já existam boas escolas pré-primárias, primárias e médias que, reorganizadas, possam servir para cursos de reciclagem do magistério em exercício.";

17. "... dar especial atenção aos cursos de formação de professores do primeiro segmento do primeiro grau, particularmente os da rede pública, melhorando a qualidade de seu ensino e, sobretudo, instituindo uma $4^{a}$. série de estágio com duração de cinco horas diárias a serem prestadas em escolas credenciadas...";

18. "Os Institutos de Educação deverão ser totalmente reestruturados para funcionar como Escolas de Demonstração. Pelo menos um deles 
deverá ser planejado para funcionar experimentalmente como nossa primeira Escola Normal Superior, de modo a admitir para a carreira do magistério pessoas que tenham o segundo ciclo completo. Isso será feito mediante convênio com a Uerj ou com a Faperj." (PEE, 1983, p. 10-33).

Esta última meta é que levou a São Gonçalo o projeto de um complexo educacional. As condições ali colocadas aproximavam aquele conjunto educacional de um projeto de Escola de Demonstração: as três unidades eram do Estado; cada uma de um nível de ensino; a faculdade era para formar professores; havia área disponível para construção de outras unidades, como escola-parque, refeitório, e um local para receber os professores que fossem estagiar nessas unidades. Este sonho de Darcy Ribeiro estava apoiado em concepção herdada de seu mestre, Anísio Teixeira.

Anísio Teixeira (1994, p. 149-150), logo após a publicação do Plano Nacional de Educação (PNE) que se seguiu à homologação da Lei no 4.024 , de 20 de dezembro de 1961 - Lei de Diretrizes e Bases da Educação Nacional (LDB) -, ofereceu, em 1962, quando diretor do Instituto Nacional de Estudos Pedagógicos (Inep), sugestões para viabilizá-lo, considerando que:

Esse plano, mais do que pedagógico ou administrativo, é um plano político, pelo qual se faz possível uma ação conjunta, [...] de todos os serviços públicos locais, municipais e estaduais na tarefa suprema e comum do estado democrático, de oferecer a todos oportunidades iguais de educação.

Em seu projeto de implantação do plano discriminava o aparato escolar com o qual cada localidade deveria contar, variando de acordo com o número de habitantes; as capitais deveriam ter sistemas escolares completos. Afirmava que a eficácia do plano dependia da preparação dos professores, que as leis são necessárias para tornar reformas possíveis, mas que as leis não fazem reformas. "Estas se fazem pela mudança de estrutura da sociedade e pelo preparo e aperfeiçoamento do professor" (Teixeira, 1994, p. 153). Propunha, para tanto, centros de treinamento que viabilizassem novas modalidades de formação de magistério para aqueles que tivessem concluído o ginásio ou o colégio. Descrevia estes centros como Escolas de Demonstração.

Tais centros serão substancialmente centros de demonstração de ensino, desde o nível de jardim de infância até a última série do ensino do segundo nível, com jardins de infância, escolas primárias e escolas de segundo nível, nos quais grupos de estagiários entre 200 e 300 virão residir, como internos, para praticar e estudar as artes do magistério infantil, primário e médio.

Os estudos serão rigorosamente articulados com essa prática direta do ensino. As escolas - funcionando como hospitais de clínicas nas escolas de medicina -, organizadas sob a forma de Escolas de Demonstração, escolas experimentais e escolas de prática, devem ter a amplitude necessária para permitir o treino individual. Ao lado das Escolas de Demonstração e experimentais, haverá escolas de prática, com classes com número suficiente para o treinamento individual, aproveitando-se as próprias escolas do sistema escolar próximo. (Teixeira, 1994, p. 154). 
Anísio Teixeira propunha a criação de 40 centros nos 22 Estados do Brasil. Considerava que a preparação do professor deveria levar em consideração que, com a massa de informações disponíveis pelos meios de comunicação, o professor deixava de ser um informante privilegiado e de autoridade indiscutível para se tornar um integrador de conhecimentos e formador do juízo crítico do aluno. Segundo o autor, o novo mestre não pode ser a jovem adolescente recém-saída da escola de ensino médio e que optou pelo magistério por considerar uma profissão adequada ao sexo feminino. O novo professor deve ser amadurecido e ter escolhido o magistério por vontade própria. Os candidatos ao magistério seriam recrutados entre jovens maiores de 18 anos e teriam formação durante um, dois ou três anos, de acordo com os alunos que fossem ficar sob sua responsabilidade. Os professores do colegial continuariam a ser formados em faculdades de filosofia.

Darcy Ribeiro (1986), que sempre explicitou a influência que Anísio Teixeira teve sobre ele, incorporava a compreensão de que a escola para povo com acentuada estratificação social torna-se mais complexa e difícil de operacionalizar, pela diversidade de condições e de alunos que deve atender, pela precária formação e desvalorização do professor e pela pouca compreensão que as autoridades têm sobre as repercussões sociais da falta de investimento em educação. O I PEE tinha este entendimento como eixo, e foi com vista a enfrentar estas carências que foi projetada - entre outras propostas de formação do professor, inicial ou em serviço - a Escola de Demonstração. Fica evidente, nas palavras de Darcy Ribeiro, a incorporação das concepções de Anísio Teixeira, visível tanto na terminologia como nos argumentos.

[...] a estruturação de um Programa de Aperfeiçoamento do Magistério em Exercício. Este, não podendo reduzir-se a ciclos e palestras verbais [...] deve ser realizado em Escolas de Demonstração, que possibilitem aos professores ver a prática da arte de ensinar linguagem, desenho, matemática ou ciências, com diferentes métodos, para efeito de avaliação, de comparação e de treinamento. Não tendo experiência nesse campo, uma vez que nosso equivalente são as velhas Escolas de Aplicação, estamos desafiados a planejar cuidadosamente esses novos centros de treinamento. É evidente que eles não devem reproduzir o objetivo da Escola de Aplicação, que era alcançar altos níveis de excelência no atendimento ao alunado proveniente de classes privilegiadas. Prevemos a instalação de pelo menos 5 desses Centros de Demonstração para o aperfeiçoamento e reciclagem do pessoal docente.

[...] Ninguém duvida de que o médico, por exemplo, precisa de uma residência hospitalar para dominar o tirocínio de sua carreira vendo os doentes serem diagnosticados e tratados por doutores experimentados. É também óbvio que o engenheiro necessita de estágios em obras, onde veja e ajude a execução de projetos semelhantes aos que estudou nos livros ou ouviu nas aulas. O professor necessita também de um estágio de treinamento em serviço. Ainda mais que os médicos e engenheiros, dada a deficiência e a precariedade dos 3 anos de curso médio, profissionalizante, a que se reduziu a formação oficial do normalista. A receptividade dos próprios professores recém-ingressados no magistério a um programa de treinamento é a mais aberta possível. Eles próprios 
sentem a necessidade imperativa dessa ajuda para que possam ter um desempenho profissional responsável. (PEE, 1985, p. 20).

Darcy Ribeiro terminava sua exposição de motivos afirmando que, devido à complexidade da tarefa do professor - de receber uma criança ainda em formação, mas já dotada de humanidade, para capacitá-la a ser cidadã de sua cultura -, tinha convicção de que o ensino normal deveria passar para nível superior, com curso de quatro anos em universidade, tanto para o professor alfabetizador como para qualquer outro especialista em educação. Para ele, a tarefa do professor era mais desafiante e difícil que a do médico. Por outro lado, reconhecia que não poderíamos esperar esse professor universitário ficar pronto; era indispensável oferecer aos professores atuais, que ensinarão milhões de crianças nos próximos anos, formação continuada, para que prossigam aprimorando-se em suas carreiras, daí a necessidade da Escola de Demonstração.

\section{Proposta e condições do Cesg}

A proposta do Cesg - fácil de imaginar, mas difícil de realizar - era integrar, pedagógica e administrativamente, as três unidades, e construir no Patronato tudo o que fosse necessário para essa integração, aproximando cada unidade das metas educacionais já descritas: o $1^{\circ}$ grau deveria extinguir o terceiro turno e proporcionar cinco horas diárias na escola (meta 1); o Cesg contaria com escola-parque para atender, prioritariamente, aos alunos do $1^{\circ}$ grau (meta 13$)$; o pré-escolar seria desmembrado do $1^{\circ}$ grau, para que as unidades de pré-escolar, $1^{\circ}$ e $2^{\circ}$ graus, por meio de integração vertical e horizontal, constituíssem uma Escola de Demonstração (meta 16); a Escola de Demonstração deveria receber professores de todo o Estado do Rio de Janeiro para serem atualizados mediante estágios, aulas e debates (meta 2); o $2^{\circ}$ grau priorizaria formação geral diurna, eliminando, aos poucos, os cursos profissionalizantes e estimulando o ingresso na FFP (meta 17); a faculdade seria reestruturada para articular-se às três unidades que ofereceriam estágios para seus alunos; os cursos de licenciatura curta seriam extintos e o horário diurno, priorizado; seria instalada na faculdade uma escola normal superior (meta 18).

Para dar uma dimensão do projeto, basta exemplificar com as obras necessárias: construção de um prédio para o pré-escolar; de várias salas de aula, para viabilizar a extinção do $3^{\circ}$ turno; de instalações para a escola-parque, mesmo aproveitando-se auditórios, oficinas e bibliotecas da faculdade e do $2^{\circ}$ grau; instalações esportivas, para atender às quatro unidades; restaurante industrial, para servir a todos os alunos e professores em horário integral; espaço adequado para hospedar professores de outras cidades que viessem estagiar no Cesg; reforma completa da escola de $1^{\circ}$ grau. Condição para as obras: o Estado ganhar na Justiça a posse do terreno do Patronato. Um projeto grandioso. Seu custo superaria tudo o que já estava instalado. O aspecto obra constitui 
exemplo de inviabilidade do projeto Cesg sem um planejamento criterioso, seja para sua implantação, seja para ganhar credibilidade.

A integração pedagógica das unidades, aspecto definidor do projeto, foi esboçada: a instalação de um conselho curricular, com a participação do diretor de cada uma das quatro unidades, além do diretor geral do Cesg. Esse conselho seria composto por professores de alta competência e experiência reconhecida em sua área de estudo. Haveria representantes de linguagem, ciências físicas, ciências biológicas, artes plásticas, literatura, etc. O objetivo desse conselho seria reformular o desenho curricular, do pré-escolar à FFP, e acompanhar sua implantação de forma que houvesse continuidade e coerência entre o que os alunos aprendiam nas escolas básicas e o estágio que os alunos da faculdade fariam nessas escolas. Tarefa gigantesca, quando materializamos um universo de cerca de 5.000 alunos e 500 professores no ano de 1984.

Em fevereiro de 1984, na metade do prazo de 90 dias que o grupo de trabalho teria para apresentar seu relatório, foi publicado em Diário Oficial o ato de criação do Cesg (Rio de Janeiro (Estado). Comissão..., 1984a). Este único documento oficial sobre o Cesg designou as unidades-membro pertencentes à Secretaria Estadual de Educação (SEE), previu a criação do pré-escolar, a nomeação de um diretor geral, de diretores das unidades e de integrantes de uma equipe de currículos, e entregava o comando do projeto à Diretoria de Desenvolvimento de Recursos Humanos (DRH) da Fundação de Amparo à Pesquisa do Estado do Rio de Janeiro (Faperj). Ainda em fevereiro foram nomeadas as diretoras da faculdade e das escolas de $1^{\circ}$ e de $2^{\circ}$ graus: nenhuma era de São Gonçalo ou do Partido Democrático Trabalhista (PDT). A direção geral foi exercida cumulativamente pela diretora do DRH da Faperj, única pertencente ao partido do governo. A diretora do pré-escolar só foi designada mais tarde, única gonçalense.

As duas condições de viabilização do Cesg não foram atendidas de imediato: um plano de implantação e a posse do terreno. Assim começou uma longa série de improvisos que marcou a história desse projeto. Foi organizada uma semana de planejamento para os professores que se baseou mais em profissionais disponíveis do que em metas a serem atingidas ou necessidades de cada unidade, que, a rigor, eram desconhecidas. O professor Darcy Ribeiro, que proferiu a aula inaugural, visitou cada unidade, vendo de perto as dificuldades de cada uma.

A faculdade vinha de um ano bastante tenso: em 1983 passara da tutela da Faperj para a Uerj; o corpo docente, horista, não era concursado e reivindicava concurso interno, e não público, para professor efetivo. Com a passagem para a Uerj, acrescentaram mais uma reivindicação: equiparação salarial aos professores. Com o retorno da FFP à Faperj, o diretor nomeado, além de lidar com a frustração do corpo docente, teria que enfrentar os alunos para priorizar os cursos diurnos. Para colocar essa reforma em andamento, em 1983 só houve vestibular para os cursos diurnos, com currículo novo, e não foram abertas matrículas iniciais para os cursos de licenciatura curta. 
Quando o Cesg começou a ser implantado, em 1984, foi visto com profunda reserva tanto pelo corpo docente quanto pelo discente; não ter havido vestibular foi considerado que o projeto fecharia a faculdade. Não era esta a intenção, mas como argumentar a favor de qualidade de ensino acabando com os cursos noturnos da única faculdade acessível de uma região onde a maioria dos jovens trabalha durante o dia? Como motivar professores para trabalhar em turno diferente do que estavam habituados, a lidar com um novo currículo, a criar uma escola normal superior sem chegar a um acordo sobre suas reivindicações?

A escola de $2^{\circ}$ grau passaria por problema semelhante ao da FFP no tocante à expectativa dos alunos: a maior procura concentrava-se no turno da noite para os cursos profissionalizantes. O projeto visava dar boa formação geral em cursos diurnos, oferecendo acesso automático aos alunos oriundos da escola de $1^{\circ}$ grau do Cesg. Estas diretrizes trariam duas frustrações: para os alunos com acesso automático, que preferiam cursos profissionalizantes noturnos; para os outros candidatos a vagas de $2^{\circ}$ grau, que se sentiam preteridos pelo acesso automático dos alunos do Cesg. O CIWO, ao contrário da faculdade, esforçou-se para superar esse impasse e efetuar mediações entre as expectativas locais e a perspectiva geral do projeto.

Os problemas do $1^{\circ}$ grau começavam fisicamente: a escola estava deteriorada, lotada com 3.200 alunos distribuídos em 72 turmas, em quatro turnos ininterruptos; as carteiras eram insuficientes para o número de alunos; à noite, nove salas de aula eram cedidas para uma unidade da Campanha Nacional de Escolas da Comunidade (CNEC); as outras nove salas eram ocupadas com um curso supletivo, modalidade de ensino que não era prevista pelo Cesg, pois a meta do governo para educação juvenil ainda estava sendo desenvolvida. O pré-escolar herdou os 100 alunos do Programa de Ampliação de Educação Pré-Escolar (Paepe) da escola de $1^{\circ}$ grau. ${ }^{5}$ Desmembrado do $1^{\circ}$ grau, o pré-escolar não possuía sala de aula, prédio próprio, mobiliário, qualquer tipo de material didático ou administrativo, de consumo ou permanente; também não contava com pessoal docente, administrativo ou de serviço.

\section{Breve histórico da Faculdade de Formação de Professores (FFP)}

A FFP foi criada em 1971, no último governo anterior à fusão do Estado do Rio de Janeiro com o Estado da Guanabara. O Centro de Treinamento de Professores do Rio de Janeiro (Cetrerj), mantenedor da faculdade, chegou a ser considerado o laboratório para licenciaturas curtas de todo o País (Nunes, 2004), criado para treinar professores em atividade atendendo às novas exigências da Lei no 5.692/71 (Brasil, 1971). "Na estrutura deste centro foi criada a Faculdade de Formação de Professores, que passou a funcionar em setembro de 1973, oferecendo as chamadas Licenciaturas de $1^{\circ}$ grau em Letras, Ciências e Estudos Sociais..." (Ayres, 2006, p. 236). Os cursos da FFP ofereciam licenciatura

\footnotetext{
${ }^{5}$ Programa que atendia a crianças na idade de pré-escolar em atividades fora da sala de aula, orientadas por uma professora auxiliada pelas mães dos próprios alunos.
} 
curta em ciências, para atuação com matemática e biologia; letras, para habilitação em português e inglês; e estudos sociais, que formaria docentes para geografia e história.

Para o funcionamento eficaz da faculdade foram criadas oficinas onde eram ministradas aulas práticas de educação para o lar, mecânica de autos, técnicas comerciais, de gráfica e encadernação, técnicas agrícolas e de comunicação e expressão. Além disso, o morro ao fundo do prédio foi utilizado para a zootecnia. Montada a estrutura física, a faculdade poderia, então, atender com sucesso às exigências pedagógicas de seus cursos oferecidos (Ayres, 2006). Segundo Vieira (2010), durante os primeiros anos a faculdade conseguiu conquistar um espaço que iria além das expectativas de seus idealizadores. Entretanto, a partir do ano de 1975, quando é realizada a fusão dos Estados do Rio de Janeiro e da Guanabara, problemas políticos e administrativos abalaram seriamente a faculdade. Neste período, a FFP troca de mantenedora duas vezes. A administração da faculdade, que se situava na própria sede, agora mudava para a cidade do Rio de Janeiro.

Em 1980, cria-se a Faperj, que se responsabilizaria por manter a FFP, porém esse período foi interrompido por dez dias de vínculo à Uerj, aumentando a instabilidade da instituição. Segundo Vieira (2010), "pode-se observar que quando a faculdade é incorporada à mantenedora, não há sequer um orçamento ou planejamento liberando recursos para a estruturação da instituição de ensino". Este fato propagava o receio do fechamento das portas da instituição às mentes de funcionários e alunos. A instabilidade só seria solucionada permanentemente após a FFP vincular-se à Uerj definitivamente. A própria história da FFP já delatava que a instituição necessitava de forte atenção, caso contrário os problemas já existentes poderiam vir de herança para qualquer projeto ali implantado (Figuerêdo, [s.d.]).

Até então os professores não dispunham de plano de carreira e eram
remunerados por hora/aula, o que dificultava o desenvolvimento de
atividades para além das de ensino de graduação. Outro problema
vivido pela instituição foi acarretado pela mudança na legislação relativa
à acumulação de cargos públicos, que provocou um esvaziamento do
quadro docente no início da década de 1980. (Ayres, 2006, p. 238-239).

\section{A implantação do Complexo Educacional de São Gonçalo}

A FFP, mantida pela Faperj, era a instituição mais ágil e mais bem assistida em termos de instalações, pessoal e material; começou, então, a ceder tudo para as outras unidades: o pré-escolar foi implantado em um conjunto de três salas à parte, que não eram utilizadas pela faculdade; absorveu professores e funcionários, além de material de todo tipo, das outras unidades, pois não existia institucionalmente, portanto não era atendida nem pela SEE nem pela Faperj. Visando a racionalização de instalações e melhor aproveitamento dos funcionários administrativos da FFP e os docentes das escolas de $1^{\circ}$ e $2^{\circ}$ graus, centralizou-se todo 
serviço de secretaria, pessoal e patrimônio no prédio da FFP, executado por funcionários da Faperj. Esses funcionários, que trabalhavam em uma única instituição à noite, passaram a atender a quatro unidades com procedimentos diversos, em três turnos. A resistência para assumir as novas funções era previsível.

Funcionários da Faperj, docentes ou não, que tinham algum tipo de habilidade específica e quisessem trabalhar com alunos, eram cedidos às três unidades da SEE para organizar programação extra-classe, já que a escola-parque ainda não tinha se concretizado. Assim, utilizando-se instalações do CIWO ou da FFP, tanto oficinas e laboratórios como bibliotecas e auditórios, foram criadas atividades opcionais para os alunos em turno complementar ao seu, ou seja, o princípio da escola-parque. Finalmente, a extinção do $3^{\circ}$ turno da escola de $1^{\circ}$ grau foi efetivada, contando-se com a disponibilidade de 12 salas de aula da faculdade, no turno da manhã e da tarde, ocupadas à noite pelos universitários.

O prédio era inadequado para abrigar crianças que não tinham limites de comportamento ou hábitos de higiene bem formados, poder de concentração pequeno diante de janelas panorâmicas e uma vontade incontrolável de descobrir o mundo sem muros que as detivessem. As carteiras de tipo universitário não facilitavam em nada a coordenação motora das crianças; os cartazes coloridos que as professoras colavam no quadro-negro eram sistematicamente arrancados pelos universitários, revoltados com a sujeira e a confusão que as crianças aprontavam. Para piorar, as turmas escolhidas para estudarem no prédio da FFP foram as de $1^{\mathrm{a}}$ e as de $5^{\mathrm{a}}$ séries, porque eram as turmas iniciais para implantação do PEE. Na prática, significava que tanto um grupo quanto outro era novo, mas com faixas etárias, necessidades, cuidados e comportamentos diferentes, em local inadequado, com a direção da escola situada a 1,5 km da FFP. No primeiro encontro pedagógico do Cesg, em maio de 1984, alguns professores criticaram a ausência de um projeto escrito que pudesse ser discutido e a implantação sem infraestrutura, sem planejamento, com carência de professor, apontando que o projeto estaria fadado a ficar no papel, já que desconhecia a realidade anterior de São Gonçalo.

No primeiro semestre de 1984, em meio a projetos culturais promovidos pelo Cesg, que, de outra forma, não chegariam a São Gonçalo, começou uma greve dos alunos da FFP que durou de maio a junho. Os universitários queriam garantias de que a faculdade não seria fechada, de que haveria contratação de professores e de que os alunos do $1^{\circ}$ grau sairiam de suas instalações. As reivindicações dos alunos revelavam as mesmas preocupações dos professores: haveria continuidade? A diretora da FFP pediu demissão e ficou demissionária durante toda a greve. Com o acerto entre Faperj, alunos e professores de que haveria vestibular para os cursos diurnos em agosto e de que seria proposto um plano de carreira aos professores para depois haver concurso, contemporizou-se a presença dos alunos do $1^{\circ}$ grau, e a greve acabou.

Os professores da FFP retornaram com novo alento, não apenas diante da expectativa de um plano de carreira que lhes permitisse tempo 
contínuo como também pelas articulações para substituição da diretora demissionária, que ocorreu em julho, sendo nomeada uma professora da casa para ocupar a direção. Os professores assumiram sua participação em comissões importantes para integração do Cesg: projeto escola normal superior; proposta de estágio do currículo novo; preparação do vestibular, em conjunto com o $2^{\circ}$ grau.

Em julho foi assinado um convênio entre a Faperj e a SEE, dando à primeira a função de "orientar, coordenar e executar todas as atividades programadas com vista à concretização do Cesg" (Rio de Janeiro (Estado), 1984b). O documento definia funções e responsabilidades das mantenedoras das unidades envolvidas em relação a pessoal, instalações, patrimônio e custeio. Acrescentava que "os dispêndios que [decorressem] diretamente [desse] convênio [seriam] eventual e oportunamente atendidos com o empenho de verbas orçamentárias específicas".

Agosto inaugura novas perspectivas: o vestibular diurno é realizado; a nova diretora da FFP inspira confiança aos seus professores; as obras começam na escola de $1^{\circ}$ grau; iniciam-se as articulações para representação no conselho curricular. Nesse momento realiza-se o $3^{\circ}$ Encontro Pedagógico do Cesg, que tem como desdobramento duas comissões com representantes de cada unidade: espaço físico, já que a posse do Patronato continuava um impasse; e estatuto do Cesg.

As articulações para a estruturação da escola-parque, que não contava com prédio próprio, mas já dispunha de atividades complementares em andamento, transcorreram paralelamente às da composição do conselho curricular. E a escola-parque, que naquele momento cedera sua função aos animadores culturais dos Cieps, projeto educacional prioritário sendo implantado, perdeu-se em discussões que não levaram à sua efetivação. No ano seguinte, o livro Falas ao professor explicou a desativação desse projeto:

[...] verificação da inconveniência de multiplicarem-se Centros Culturais Comunitários ou as Escolas-Parques, previstos para atender as crianças por mais 5 horas, antes ou depois das aulas. Isto porque só se contava com escolas de eficácia comprovada nas áreas mais antigas e mais ricas, no Estado e na cidade, o que conduzirá a privilegiar os já privilegiados, caso se lhes acrescentasse tal atendimento. Em lugar disso, optou-se pela multiplicação do que é o modelo de ensino público em quase toda parte, que é uma escola de dia completo. (PEE, 1985, p. 12).

Em outubro o plano de carreira para os professores da FFP ficou pronto, entretanto a Faperj, diante do impacto na folha de pagamento mensal, decidiu não efetivá-lo: os professores entraram em greve, a diretora da FFP pediu demissão e a diretora do DRH da Faperj, que respondia pela direção geral do Cesg, pediu sua exoneração. Com sua saída, o conselho curricular recém-criado desarticulou-se inteiramente. O Conselho Estadual de Educação (CEE) interveio na FFP, designando seu professor mais antigo para responder pela direção. Não havia mais ambiente para os professores da FFP integrarem o projeto. O novo diretor, gonçalense, 
além da má vontade geral, tinha interesses políticos diversos dos do PDT, pois estava ligado ao grupo do governo municipal vigente.

Com a omissão da mantenedora, que causou graves dificuldades de ordem material, e a perda de importância do Cesg pela implantação dos Cieps, restou a perspectiva de um trabalho conjunto entre as três unidades de ensino básico. No final do ano foi encaminhada uma carta ao professor Darcy Ribeiro relatando a importância política do projeto Cesg para São Gonçalo e os passos necessários para sua efetivação. Enquanto não se tinha resposta, as unidades passaram a fazer encaminhamentos por decisão própria: as três unidades da SEE desmembraram os serviços de secretaria, pessoal e patrimônio, retornando cada um para seu próprio prédio, permitindo aos funcionários da Faperj optar entre acompanhar ou não o serviço para a unidade da SEE; as salas cedidas da FFP passaram a receber alunos em processo de alfabetização (CA, $1^{\text {a }}$ e $2^{\mathrm{a}}$ série), todos sob responsabilidade da diretora do pré-escolar, pois, apesar das condições continuarem inadequadas, trabalhava-se com faixa etária contínua e sob única direção exercida no local. Apesar do afastamento da FFP do Cesg, seus alunos iniciaram estágios, de acordo com o currículo novo, nas unidades da SEE. Como não houve planejamento, o critério de escolha de turmas foi feito mediante o horário da faculdade, prejudicando o desenvolvimento do currículo novo. Mesmo assim, alguns professores da FFP se empenharam bastante.

A carta enviada ao professor Darcy Ribeiro (Complexo Educacional, 1985) teve desdobramento em maio, quando ele criou uma comissão para propor a reestruturação do Cesg, particularmente da FFP. Este encaminhamento revelou que o projeto ainda estava entre as preocupações de seu idealizador. Esta comissão funcionou como um catalisador, proporcionando a retomada de contato regular das unidades da SEE com a FFP. Ao começar 1986, dois obstáculos continuavam a inviabilizar o Cesg: o problema do espaço físico para abrigar todas as crianças do pré-escolar à $8^{\mathrm{a}}$ série durante cinco horas por dia, com a construção de um Ciep, ou em horário integral, com a construção de dois Cieps no terreno que continuava a ser disputado na Justiça; e a abertura do vestibular da FFP, sem o que jamais se conseguiria recuperar a participação dos professores da faculdade no projeto. Este segundo problema agravava o primeiro, pois, com alunos novos na faculdade, as salas não poderiam mais ser cedidas.

Em março de 1986, o professor Darcy Ribeiro foi convencido da necessidade de desapropriar o terreno do Patronato; encontrada forma jurídica que viabilizasse a desapropriação sem ônus para o Estado, pois a rigor o terreno pertencia a ele, ela foi efetivada e os Cieps começaram a ser construídos. O problema espaço transformou-se numa questão de tempo. Paralelamente, as unidades da SEE apoiaram o diretor na sua decisão de realizar o vestibular, mesmo sem o consentimento da Faperj, que ainda não resolvera a situação trabalhista dos professores e, portanto, não queria contratar outros, consequência inevitável de mais um vestibular. Com a mudança da SEE, do presidente da Faperj e do presidente do PEE, o apoio para o vestibular e para o desenvolvimento do Cesg foi garantido. 
Com a derrota do professor Darcy Ribeiro e do PDT para o governo do Estado, a continuidade do projeto por meio de convênio interinstitucional ficou inviabilizada. Restou a possibilidade de institucionalizar a integração que já se dera entre as três unidades da SEE. Esta possibilidade materializou-se no Decreto $n^{0}$ 9.730, de 6 de março de 1987, assinado pelo governador, e na Resolução no 1.371, de 12 de março de 1987, assinada pela secretária estadual de Educação. Esses documentos continham tudo o que as unidades da SEE buscaram durante três anos, mas só foram oficializados na última semana de governo, na esperança de que pudessem servir de apoio à continuidade do projeto. Só que as condições políticas para a continuidade não mais existiam.

\section{Referências bibliográficas}

AYRES, A. C. M. Tensão entre matrizes: um estudo a partir do curso de Ciências Biológicas da Faculdade de Formação de Professores/ Uerj. 2006. Tese (Doutorado em Educação) - Universidade Federal Fluminense, Niterói, 2006.

BRASIL. Congresso Nacional. Emenda Constitucional no 18, de 30 de junho de 1981. Dispõe sobre aposentadoria especial para professores e professoras. Diário Oficial da União, Brasília, 9 jul. 1981. Disponível em: http://www.planalto.gov.br/ccivil 03/constituicao/emendas/ emc_anterior1988/emc18-81.htm>.

BRASIL. Lei no 4.024, de 20 de dezembro de 1961. Fixa as Diretrizes e Bases da Educação Nacional. 1961. Diário Oficial da União, 27 dez. 1961. Disponível em: <http://www.planalto.gov.br/ccivil_03/Leis/ L4024.htm>.

Lei $n^{\circ}$ 5.692, de 11 de agosto de 1971. Fixa diretrizes e bases para o ensino de $1^{\circ}$ e $2^{\circ}$ graus, e dá outras providências. Diário Oficial da União, 5 ago. 1971. Disponível em: < http://www.planalto.gov.br/ ccivil_03/Leis/L5692impressao.htm>.

COMPLEXO EDUCACIONAL DE SÃO GONÇALO. Conselho Diretor. Carta ao professor Darcy Ribeiro. São Gonçalo: dezembro de 1984. - Relatório à Comissão de Reestruturação do CESG. São Gonçalo: julho de 1985; novembro de 1985.

FIGUERÊDO, Haydée da Graça F. Investigando um lugar de memória. Projeto de Pesquisa. São Gonçalo: Faculdade de Formação de Professores, [s.d.]. [Não publicado]. 
LOPES, E.; GALVÃO, A. M. História da Educação. 2. ed. Rio de Janeiro:

DP\&A, 2005.

MAURíCIO, Lúcia Velloso. Por que picharam a escola? Experiência de democratização em escola pública de $1^{\circ}$ grau. 1980. 241 p. Dissertação (Mestrado em Educação) - Instituto de Estudos Avançados em Educação (Iesae/FGV), Rio de Janeiro, 1990.

NUNES, Clarice. Visões da História da Educação: entre práticas, representações e identidades (2001-2004) - relatório final. Rio de Janeiro, 2004.

PROGRAMA ESPECIAL DE EDUCAÇÃO (PEE). Falas ao professor. Rio de Janeiro: Fundação de Amparo à Pesquisa do Rio de Janeiro, 1985. 52 p.

. [Diretrizes educacionais para o governo Brizola reformuladas após o Encontro de Professores do Primeiro Grau da Rede Pública do Rio de Janeiro, ocorrido na cidade de Mendes, RJ]. Escola Viva, [jornal], Rio de Janeiro, n. 2, p. 10-33, dez. 1983.

RIBEIRO, Darcy. O livro dos CIEPs. Rio de Janeiro: Bloch, 1986.

RIO DE JANEIRO (Estado). Comissão Coordenadora de Educação e Cultura do Rio de Janeiro. Ato do Presidente, 7 de fevereiro de 1984. Diário Oficial, Rio de Janeiro, p. 4, 10 fev. 1984a.

RIO DE JANEIRO (Estado). Decreto no 3.290, de 26 de junho de 1980.

RIO DE JANEIRO (Estado). Decreto n 9.730, de 6 de março de 1987. Diário Oficial, Rio de Janeiro, p.4-5, 9 mar, 1987.

RIO DE JANEIRO (Estado). Fundação de Amparo à Pesquisa do Estado; Secretaria de Estado de Educação. Convênio de 24 de julho de 1984, Processo no 16/009/84. 1984b.

RIO DE JANEIRO (Estado). Secretaria de Estado de Educação. Resolução SEE no 1.371, de 12 de março de 1987. Diário Oficial, Rio de Janeiro, p. 71, 14 mar. 1987.

TEIXEIRA, Anísio. Educação e a formação nacional do povo brasileiro. In: . Educação não é privilégio. 5. ed. Rio de Janeiro: Ed. UFRJ,

1994.

VIEIRA, David de Paula Rodrigues. Complexo Educacional de São Gonçalo: propostas de novas perspectivas para a educação.

São Gonçalo: Faculdade de Formação de Professores da Uerj, 2010. [Monografia]. 
VINCENT, Guy; LAHIRE, Bernard; THIN, Daniel. Sobre a história e a teoria da forma escolar. Educação em Revista, Belo Horizonte, n. 31, p. 7-48, jun. 2001.

Lúcia Velloso Maurício, doutora em Educação pela Universidade Federal do Rio de Janeiro, é professora adjunta da Faculdade de Formação de Professores da Universidade do Estado do Rio de Janeiro (Uerj).

luciavelloso.uerj@gmail.com

Recebido em 16 de junho de 2011.

Aprovado em 17 de janeiro de 2012. 